\title{
ARTIGOS
}

\section{ESTUDANTES DE ENGENHARIA: ENTRE O EMPODERAMENTO E O BINARISMO DE GENNERO'}

ADRIANA ZOMER DE MORAES'

TÂNIA MARA CRUZ"

\section{RESUMO}

Este artigo trata, a partir de entrevistas com estudantes de Engenharia (2014), de suas experiências acadêmicas e concepções de gênero em relação ao campo profissional. 0 materialismo histórico e dialético, como referencial, visa a estabelecer as conexões entre o particular e a totalidade social, e entre a subjetividade e a objetividade no processo histórico de transformações e permanências. O aumento do ingresso das mulheres nas engenharias exige contínuo enfrentamento das estudantes, que expressam estratégias de empoderamento contraditoriamente acompanhadas de atributos sustentados em binarismos de gênero. Por sua vez, os colegas e os professores tendem a reforçar a divisão sexual do trabalho em novas formas.

ESTUDANTES • ENGENHARIA • TRABALHO • RELAÇÕES DE GÊNERO

Centro Universitário Barriga Verde (Unibave) Orleans (SC), Brasil: azomermoraes@gmail.com

Universidade do Sul Santa Catarina (Unisul), Tubarão (SC), Brasil tania.cruz@unisul.br

Pesquisa financiada pelo projeto Antropologia, Gênero

e Educação em Santa

Catarina (Fapesc/CNPc n. 06/2012 - Pronem, 2013

-1016); outro recorte desta pesquisa foi publicado em MORAES, A. Z.; CRUZ, T. M.

Engenharias: sexismo

espaços (re)partidos e a

formação. In: WELTHER

Tânia; GROSSI, Miriam Pillar GRAUPE, Mareli Eliane (Org.)

Antropologia, gênero e educação em Santa Catarina.

1. ed. Tubarão: Copiart:

Mulheres, 2017. p. 97-116

\section{ENGINEERING STUDENTS: BETWEEN EMPOWERMENT AND GENDER BINARISM}

\section{ABSTRACT}

This article, based on interviews with ninth semester engineering students (2014), deals with their academic experiences and conceptions of gender in the professional field. The dialectical and historical materialism, as a reference, aims to establish connections between the private and the social totality and between subjectivity and objectivity in the historical process of transformations and permanence. The increase in the number of admissions of women in engineering programs demands a continuous confrontation offemale students who express empowerment strategies paradoxically accompanied by attributes supported by gender binarism. In turn, colleagues and teachers tend to reinforce the sexual division of work in new ways. STUDENTS • ENGINEERING • LABOUR • GENDER RELATIONS 
RÉSUMÉ

Cet article présente une analyse, menée à partir d'entretiens avec des femmes étudiants ingénieurs (2014) sur leurs expériences académiques et leurs conceptions sur l'égalité des genres dans le domaine professionnel. En prenant comme référentiel le matérialisme historique et dialectique, cette étude vise à établir les connexions entre le particulier et la totatilité du social, ainsi qu'entre la subjectivité et l'objectivité dans le processus historique de transformations et de permanences. La présence accrue des femmes dans les cours d'ingénierie implique des affrontements continus de la part des étudiantes qui ont recours à des stratégies d'empowerment, paradoxalement accompagnées d'attributs renvoyant au binarisme de genre. De leur côté, leurs collègues mâles et les enseignants ont tendance à renforcer la division sexuelle du travail par de nouveaux moyens.

ÉTUDIANTES・INGÉNIERIE・TRAVAIL・RELATIONS DE GENRE

\section{ESTUDIANTES DE INGENIERÍA: ENTRE EL EMPODERAMIENTO Y EL BINARISMO DE GÉNERO}

RESUMEN

Este artículo trata, a partir de entrevistas con estudiantes de Ingeniería del noveno periodo (2014), de sus experiencias académicas y concepciones de género en relación al campo profesional. El materialismo histórico y dialéctico, como referencial, pretende establecer las conexiones entre lo particular y la totalidad social, y entre la subjetividad y la objetividad en el proceso histórico de transformaciones y permanencias. El aumento del ingreso de las mujeres en las Ingenierías exige continuo enfrentamiento de las estudiantes, que expresan estrategias de empoderamiento contradictoriamente acompañadas de atributos sustentados en binarismos de género. Por su parte, colegas y profesores tienden a reforzar la división sexual del trabajo en nuevas formas. 

espaço produtivo brasileiro, inclusive no exercício de funções antes reconhecidas como tipicamente masculinas. No entanto, homens e mulheres ainda são valorizados de forma distinta, quando o assunto é trabalho. A discussão apresentada aqui faz parte dos esforços de pesquisadores/as brasileiros/as da área de ciência e gênero, particularmente no campo das engenharias. Como objetivos de pesquisa, buscamos, entre estudantes de Engenharia, sua concepção de gênero, como experienciam as relações de gênero no decorrer da formação universitária e se a universidade tem sido um espaço de ruptura ou permanência, diante de uma divisão sexual do trabalho altamente segmentada em masculina e feminina na área estudada. A pesquisa, norteada pelo materialismo histórico-dialético, buscou ouvir e analisar o que estudantes homens e mulheres das nonas fases de cursos de Engenharia tinham a dizer sobre as relações de gênero em uma instituição de ensino superior (IES) comunitária em Santa Catarina.

A subjetividade presente nas narrativas concentra o caráter histórico concernente à acumulação e ao processamento das experiências individuais e sociais do sujeito (GONZALEZ REY, 2005). Logo, trata-se de um sistema complexo de significações e sentidos subjetivos elaborados na vida cultural, conscientes ou não, produzindo subjetividades diferentes, conforme os contextos econômicos e sociais em que estão situadas. 
Tais narrativas, cotejadas com autores/as do campo de estudos de gênero, educação e trabalho, permitem compreender algumas facetas do processo histórico contemporâneo e o modo como determinados sujeitos constroem suas práticas sociais no espaço acadêmico dos cursos de Engenharia.

\section{CONTEXTUALIZANDO AS ARTICULAÇÕES ENTRE TRABALHO E RELAÇÕES DE GÊNERO}

Na atualidade, os sujeitos evidenciam a relevância que a esfera do trabalho adquire em suas vidas. O trabalho organiza o tempo da vida, divide-o em fases e normatiza, possibilita ou limita: da infância à velhice tem-se um trajeto estruturado em estudo, trabalho e aposentadoria. Além disso, o trabalho é colocado na posição de necessidade existencial, cujo retorno financeiro, nem sempre adequado, é buscado para a satisfação de necessidades humanas, como alimentação, moradia, educação, lazer, bem-estar social, arte e prestígio, tornando-se, portanto, um elemento que contribui para o autoconceito e identidade pessoais. Mediado pela dimensão social, o trabalho é categoria fundante do ser humano e suas formas de sociabilidade, tomando um lugar ativo na construção da subjetividade, uma vez que o sujeito se constrói no seu fazer, tanto pela atividade em si quanto pela concepção que tem a respeito dela.

Antunes (1997) aponta que as transformações contemporâneas - globalização, flexibilização das relações de trabalho, automação e a exigência de um trabalhador polivalente - produzem heterogeneização, fragmentação e complexificação da classe trabalhadora, o que repercute e altera o sujeito do trabalho, atingindo intensamente o universo da consciência, da subjetividade do trabalhador e de suas formas de representação. Nesse processo, ocorre um aumento no número de emprego e de trabalho remunerado das mulheres em nível mundial, com exceções regionais, e observa-se que, se houve a expansão da oferta de trabalho, esta foi acompanhada da precarização das suas condições (HIRATA, 2002).

No Brasil, os anos 1970 e 1980 marcaram enfrentamentos em que as mulheres trabalhadoras ampliaram sua participação nas lutas de classe e na organização política e sindical contra a inevitabilidade do destino de mãe e esposa, lutando por novas profissões,

[...] salários iguais para trabalhos iguais, além da reivindicação de uma divisão mais justa no trabalho doméstico, na esfera reprodutiva, libertando, ao menos parcialmente, a mulher da dupla jornada. (NOGUEIRA, 2010, p. 19)

A participação ativa e crescente da força de trabalho feminina na economia produz alterações em uma rede complexa de relacionamentos. 
Se, ao transformar a realidade social, os indivíduos se modificam, a atividade de mulheres em cargos antes improváveis transforma o mercado de trabalho e possibilita a constituição de novas formas de subjetividade.

Para a maior parte das mulheres de famílias trabalhadoras, o universo patriarcal pouco se alterou: o homem permaneceu na condição de provedor principal e a mulher continuou a ser vista como coadjuvante e responsável pela casa e pelos filhos, reificando a divisão sexual desigual do trabalho (NOGUEIRA, 2010). Tal situação se altera, mas se agrava quando a mulher se torna a única provedora com baixos salários em uma família monoparental, com sobrecarga doméstica, ao morar sozinha com seus filhos. Por outro lado,

[...] entre 1995 e 2015, a taxa de participação feminina pouco oscilou em torno dos 54-55\%, não tendo jamais chegado a 60\%. Isso significa que quase metade das brasileiras em idade ativa está fora do mercado de trabalho (BRASIL; ONU MULHERES, 2016, p. 2),

provavelmente em decorrência da falta de espaços educativos infantis.

Parte das mulheres de setores médios e altos passa a delegar as atividades com a casa e filhos a outra mulher - a empregada doméstica. Contudo, a maternidade transferida, aparente opção de trabalho para as mulheres pobres, mantém essas mulheres atadas aos baixos salários e à precarização (COSTA, 2002). A luta pela igualdade entre os sexos proporcionou algumas conquistas, mas, pelos vieses de classe e raça, terminou por reforçar a dominação de outras mulheres: em 2015 havia 519.992 trabalhadoras domésticas no país, das quais 312.558 eram negras, e com maior coeficiente sem carteira assinada (BRASIL; ONU MULHERES, 2016).

Por outro lado, a luta feminista, que trouxe conquistas educacionais e profissionais para mulheres dos setores médios, encontra entraves nos guetos da educação superior, na ascensão da carreira ou nos salários diferenciados. Estes entraves são decorrentes de uma construção social, histórica e cultural das categorias do masculino e do feminino, indicando que as relações de gênero, enquanto sistema, estruturam a diferença hierárquica entre os sexos, refletindo-se em uma relação de opressão e dominação (KERGOAT, 2005). Para a autora, à divisão social e técnica do trabalho, está acrescida uma clara hierarquia advinda das relações entre homens e mulheres, que se reflete de modo diferenciado sobre as classes sociais e dentro da classe trabalhadora.

Essa divisão sexual do trabalho apoia-se em dois grandes pilares: de que há trabalho feminino e masculino e que este último é superior ao primeiro. O capital apropriou-se desse contexto de dominação/subordinação que o antecede, e tem reforçado econômica e culturalmente tal situação, com a falta de creche, os salários inferiores, a naturalização 
ideológica, entre outros mecanismos. A construção cultural que produz significados binários de masculinidade ou feminilidade para cada profissão é constituída nesse imbricamento entre economia e subjetividade, perpassando as instituições sociais, como família ou espaços educativos e religiosos.

Cabe esclarecer que, além de a categoria sexo biológico (ou de nascimento) não ser uma variável descartada por nós, consideramos que a categoria social de sexo, homens e mulheres, necessita ser articulada com gênero. Em outras palavras, na medida em que sexo torna visível o sujeito nas práticas sociais, a categoria gênero permite visualizar as relações entre esses sujeitos, mediadas por significados plurais de feminilidades e masculinidades, ainda predominantemente hierárquicas. A desigualdade apresenta-se de modo contraditório, pois as mulheres constroem, de forma diferente em cada sociedade, certos mecanismos de poder que lhes permitem "meter cunhas na supremacia masculina e, assim, cavar-gerar espaço nos interstícios da falocracia” (SAFFIOTI, 1992, p. 184).

O grande desafio dos estudos de gênero é compreender como as relações de gênero se concretizam nos cenários político, econômico e histórico, dos quais os sujeitos participam, e os sentidos/significados que são produzidos. Apresenta-se a necessidade de analisar o processo de inserção das mulheres estudantes de Engenharia e dos posicionamentos de homens e mulheres no espaço educativo da universidade, sem perder de vista o espaço produtivo, pensando a relação dominação/subordinação, em contextos globais e específicos.

\section{EDUCAÇÃO SUPERIOR, ENGENHARIA E GÊNERO}

No Brasil, os dados de graduandos por sexo demonstram que as mulheres, apesar de adentrarem mais do que os homens no ensino superior, predominam em cursos de Ciências Humanas e Sociais Aplicadas, áreas com menor prestígio e menor salário (ROSEMBERG; MADSEN, 2011; BRASIL, 2013). Não há uma política de equidade no que tange ao ingresso das mulheres nos diferentes cursos, e persiste a segregação, a exemplo dos altos índices de matrículas femininas em Pedagogia ou masculinas nas Engenharias (BRASIL, 2009, 2010). As mulheres nas engenharias são discriminadas em virtude do sexo/feminilidades no espaço produtivo, em um processo historicamente construído que demora em promover mudanças (BRUSCHINI, 1978).

Da década de 1990 para a de 2000 foram abertos novos cursos de Engenharia por todo o país. Em 1991, dos 13.632 concluintes de todos os cursos de Engenharia, apenas 2.251 eram mulheres. Em outras palavras, de $16,5 \%$ de mulheres concluintes no período de 2001 a 2010, tal proporção passou para um patamar de 30\% nos anos seguintes (BRASIL, 2013). 
Todavia, o diploma de engenheira não significa, necessariamente, a inserção no mercado de trabalho, e os indicativos, em períodos semelhantes, eram bem menores que um terço, registrando uma virada com alguns anos de atraso, a partir de 2005. Os órgãos representativos da profissão, como o Conselho Regional de Engenharia e Agronomia (Crea) de São Paulo, revelam que, entre 2005 e 2012, o número de mulheres credenciadas nas diferentes áreas da Engenharia subiu 142,14\% e o número de engenheiras cresceu 55,53\% de 2005 a 2013 (CALAFIORI, 2013). Segundo dados publicados pela Federação Interestadual de Sindicatos de Engenheiros (FISENGE) a partir de informações do Crea da Paraíba, as mulheres

\section{[...] são 17.875 no total de 92.478. Em 2003, eram 7.829 e repre- sentavam 15\% [...]. Em 2003, as engenheiras tinham salários que representavam em média $75 \%$ dos pagos aos seus colegas do sexo masculino. Em 2013, já obtinham remuneração equivalente a $81 \%$. (FISENGE, 2017)}

Nesse contexto, queremos refletir sobre a aprendizagem profissional nos espaços educativos, a partir das experiências relacionais de gênero neles vividas por estudantes de Engenharia. Tais experiências, que podem repercutir nas mudanças profissionais, carecem ser pesquisadas, particularmente, por quem busca uma educação emancipatória em uma perspectiva classista, que tenha por base as relações de trabalho atravessadas por outros marcadores sociais, como as relações de gênero e raça. Nas palavras de Silva e Saavedra (2009, p. 62), esses projetos de escolarização estão inseridos em forças sociais que modelam e limitam "o pensamento e a reflexão profissional, definindo identidades profissionais e posicionando tanto conhecimentos como pessoas em estruturas e relações hierárquicas na escola e na sociedade em geral”.

A constituição das subjetividades está subsumida ao modo como a escola ou a universidade organiza esse conjunto de relações, por meio de seu currículo informal ou oculto nos significados que lhe são pertinentes, de não intencionalidade programática, mas produtora de sentidos, e no que tange às questões de gênero, repletas de preconceitos e discriminações. Por isso, a concepção de currículo aqui adotada é a de Moreira e Candau (2007, p. 28), para quem o currículo é "um lugar em que, ativamente, em meio a tensões, se produz e reproduz a cultura. Currículo refere-se, portanto, à criação, recriação, contestação e transgressão".

Nesse processo contraditório de conflito, os espaços educativos e os do trabalho estão conectados e são permeáveis às disputas que ocorrem em cada um deles, em experiências estudantis e docentes, individuais ou coletivas, conservadoras ou de contra-hegemonia, na sociedade patriarcal ainda vigente. 


\section{PERCURSO METODOLÓGICO}

Apoiando-se no materialismo histórico-dialético, que compreende os seres como produtos e produtores de sua cultura e história, trazemos a ideia de constituição de sujeito e de subjetividade para a pesquisa, em interlocução indivíduo-sociedade, em que o psiquismo constitui-se socialmente, sem a dicotomia objetividade/subjetividade.

Essa abordagem busca a compreensão dos fenômenos sob o prisma de seu acontecer histórico, considerando o sujeito como instância da totalidade social, e o conhecimento como uma produção construtivo-interpretativa, que

[...] não é uma soma de fatos definidos por constatações imediatas do momento empírico. Seu caráter interpretativo é gerado pela necessidade de dar sentido a expressões do sujeito estudado, cuja significação para o problema objeto de estudo é só indireta e implícita. A interpretação é um processo em que o pesquisador integra, reconstrói e apresenta em construção interpretativa diversos indicadores obtidos durante a pesquisa, os quais não teriam nenhum sentido se fossem tomados de forma isolada, como constatações empíricas. (GONZÁLEZ REY, 2005, p. 31)

Nessa perspectiva, o/a pesquisador/a é parte essencial no processo de produção dos dados, contextualizando suas indagações, observando a qualidade da expressão dos sujeitos dentro de um contexto social e selecionando suas narrativas. Nessa abordagem, não se busca um universo numericamente representativo de sujeitos de pesquisa, já que um único sujeito pode suprir a necessidade de informações que o tema demanda.

A pesquisa foi realizada em uma IES comunitária do Estado de Santa Catarina, que conta com 435 estudantes nos cursos de Agronomia, Engenharia Civil, Engenharia de Produção e Engenharia Sanitária e Ambiental. Nestes quatro cursos, estavam matriculados 297 homens e 148 mulheres. No Gráfico 1, observa-se que, no período de 2011 a 2015, a participação feminina tem aumentado nessa instituição, conforme tendência já apontada em pesquisas sobre os anos anteriores (CARVALHO; SOBREIRA, 2008; SALVADOR, 2010). O maior número de ingressantes mulheres na Engenharia Ambiental e Sanitária ratifica outras pesquisas e revela um fenômeno nacional de crescimento neste campo, ainda que em nosso estudo tenhamos observado, também, maior desistência nessa área (LOMBARDI, 2005; MENEZES; LIMA E SOUZA, 2013). 


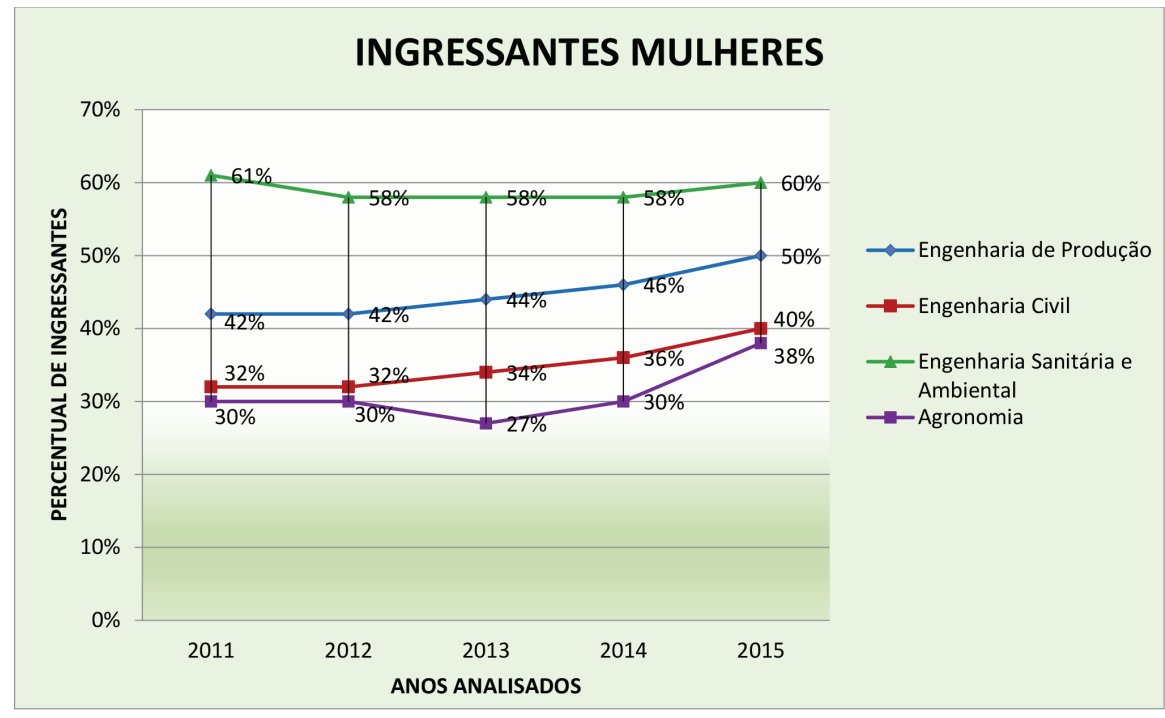

Fonte: Elaboração das autoras com base em dados fornecidos pela IES (2011-2015).

GRÁFICO 2

DISTRIBUIÇÃO DOS ESTUDANTES, POR SEXO E CURSO NA NONA FASE (2015)

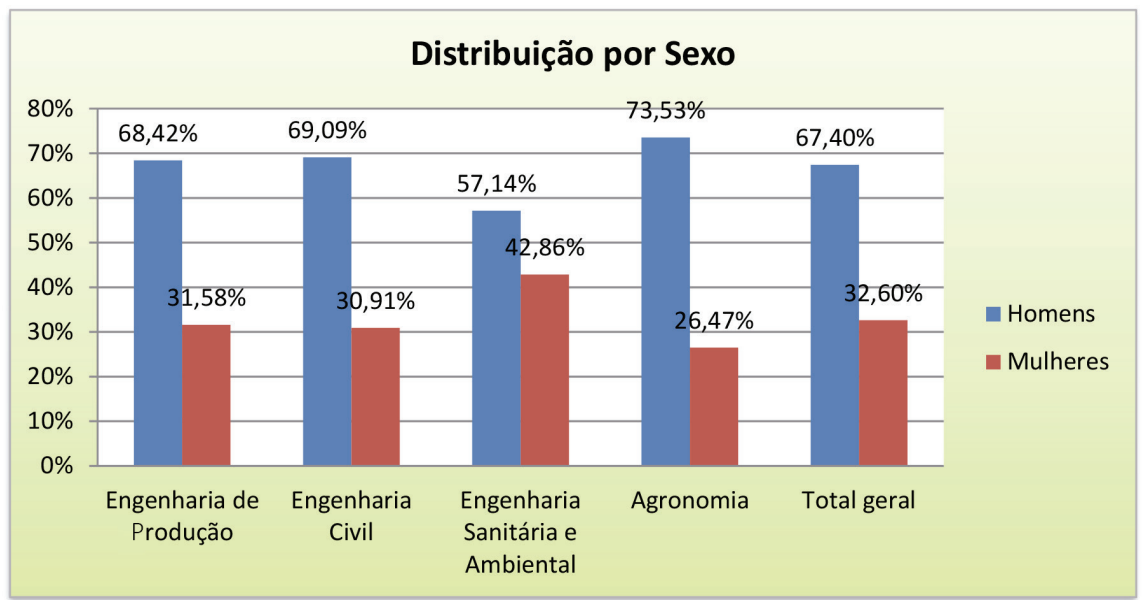

Fonte: Elaboração das autoras (2015).

Com o conjunto de 181 estudantes da nona fase, dos quais 122 eram homens e 59 mulheres, realizamos uma pesquisa exploratória que nos permitiu traçar um panorama do universo de pesquisa e refinar nosso foco de entrevista. Destacamos que o fato de não haver negros nas nonas fases reafirma a pouca presença negra no ensino superior (SANTOS; SOUZA; ATOLINI, 2016), mais ainda se a IES não for pública. Ao todo foram entrevistados 16 estudantes em 2014, sendo oito homens e oito mulheres das nonas fases dos cursos de Engenharia citados, cujos nomes são fictícios, definidos pela acessibilidade e por estarem regularmente matriculados/as. 
Para este artigo, selecionamos dois eixos de análise: o primeiro, sobre educação, escolhas e empoderamento, em que tratamos dos sentidos de poder com o ingresso e permanência de mulheres nas engenharias em suas relações com docentes, colegas e familiares; em seguida, a permanência do binarismo de gênero e suas implicações na formação de engenheiros e engenheiras.

\section{EDUCAÇÃO, ESCOLHAS E EMPODERAMENTO}

$O$ espaço que as mulheres vêm ocupando no ensino superior e em profissões reconhecidas social e historicamente como masculinas permite, a elas, colocarem-se em outra dimensão nas relações de poder-subordinação, oportunizando a criação de formas de ser e estar em suas profissões, de modo contrário aos preceitos da divisão sexual do trabalho já instituída predominantemente. Estas identidades profissionais, que começam a ser construídas ainda durante o período como estudantes de graduação, são relacionais, o que implica afirmar que os homens estudantes também são conformados nestas mesmas interações e constituem, ali, suas masculinidades para o exercício de poder fora da universidade.

No embate da constituição destas identidades coletivas, analisamos o modo como essas mulheres constroem um empoderamento que as leva a sobreviver na seara masculina das engenharias, e a não desistir do curso ou da profissão. O empoderamento não é apenas um sentimento ou consciência, pois implica ação no social que, pelo fortalecimento do sujeito, acarreta, motiva e estimula o fortalecimento dos demais membros da rede de relacionamento em situação semelhante, e está ligado à emancipação e ao crescimento profissional das mulheres (LEON, 2000). Tal conquista pode ser verificada na comparação entre os objetivos traçados e a ocorrência real desses objetivos, incluindo o sentimento por parte das mulheres, de que elas podem pôr em prática os objetivos traçados para melhorar sua condição na sociedade (SEN, 2001).

Entre as entrevistadas, a busca pelo empoderamento iniciou-se desde a escolha do curso, em interações familiares de superação, no círculo de amizades e nas análises prévias, decorrentes de suas experiências anteriores sobre os significados sociais de uma profissão que se apresenta altamente masculinizada. Depois da entrada, a permanência no curso demandou novas expressões de empoderamento diante das (im)possibilidades de construção de uma identidade profissional não hierárquica, à medida que as interações, em geral negativas, ocorriam junto a colegas e professores homens.

Com exceção de uma delas, que revelou forte obstáculo familiar, de modo geral as relações familiares tenderam à neutralidade, diferentemente do apoio citado em algumas pesquisas (VELHO; LEON, 1998; 
CASAGRANDE; LIMA E SOUZA, 2017). Contudo, o silêncio pode expressar contrariedades familiares:

Imagina que nem nosso pai, lá na propriedade, quer ouvir nossa opinião? Querem que estude, mas depois nem querem saber do que aprendemos, porque são acostumados com as mulheres em casa só obedecendo e cuidando dos filhos, tirando leite. Mulher cuidando da propriedade nunca aceitam bem. Sempre o homem leva vantagem! (Vera, $A G)^{2}$

O conservadorismo de algumas famílias, em nosso estudo de caso, situa-se nos marcos de outras pesquisas sobre cidades do interior e regiões rurais. Na condição de enfrentar essas barreiras sociais e contrapor-se à ideia de que a Engenharia é para homens, temos, no depoimento de Rita, a busca de ação para consecução de seus objetivos e forte motivação pessoal de enfrentamento contra os obstáculos resultantes das relações familiares. As considerações de Rita sobre a presença de mulheres na Engenharia é quase um manifesto, e vale sua extensa inserção aqui:

Só que eu sou mulher e escolhi o que eu gosto, tem mulher que não, faz o que o marido quer, namorado. Meu pai queria que eu fosse fazer medicina. Deus me livre! Tenho horror a sangue! Gosto de fazer cálculos, entrar na fábrica e adoro logística, uma área que é o máximo. "Médico ganha bem! Muito bem!" diz minha mãe. E, sem contar que trabalho de fábrica eles acham que é sujo, difícil. Engenheira de Produção não fica só no bem bom, não trabalha arrumadinha. Essas coisas de brinco e anel, nem pensar! [...] um dia ele me perguntou: "tu acha mesmo que os macaco velho lá da fábrica vão te obedecer?" [...] Fiquei quieta, não ia contrariar o meu pai, mas depois disse: vou ser engenheira de produção e das boas, viu pai? Eu quero ser engenheira e vou mostrar para todo mundo. "Vamos ver!" ele respondeu. Disse a ele que eu posso. Vou me preparar para comandar, mesmo que seja para comandar homens e vou conseguir fazer um bom trabalho. [...] Eu é que não fico na mão de homem, vou em frente: serei engenheira de produção! (Rita, EP)

A estratégias de priorizar a ação e o destinatário da fala deixam claro haver, também, um outro, contra o qual ela se insurgiu e insurge seguidamente - o amplo mundo masculino e as mulheres que o defen-

Os cursos serão designados por siglas: Agronomia como AG; Engenharia Ambiental e Sanitária EAS; Engenharia Civil, EC: Engenharia de Produção, EP. dent dem, até mesmo sua mãe.

Aliás, as entrevistadas citaram frequentemente as informações dadas por suas professoras sobre a realidade do mundo do trabalho como um espaço masculino e de baixos salários femininos. Ao responder o 
porquê de cursar Engenharia, Maria e Vera reafirmam a profissão de engenheiras “mesmo" vista como campo de atuação de homens.

As mulheres não fazem muito engenharia, mas eu queria e fiz.
Estou aqui, não é? [...] as mulheres entram na Engenharia e os ho-
mens olham achando que a gente não pode, mas pode sim, somos
iguais a eles. Eu acho que a gente pode fazer o curso que quiser
sendo mulher ou homem. (Maria, EP)

[...] Tem cada dia mais mulher nessa área. A mulherada está mandando bem, ocupando os espacos dos marmanjos. [...] Antes engenheiro era homem, agora estamos aqui. Eles que se cuidem! Seremos um exército de mulheres nas engenharias e daqui a pouco convencemos que somos boas! (Vera, AG)

A automotivação mostra que a preparação para enfrentamento dos espaços familiares, escolares e de trabalho não é só intelectual, mas também psicológica, de autoconvencimento diante das pressões masculinas de opressão. A escolha da profissão torna-se um claro exercício de contra-hegemonia em um processo que tem início no curso, mas segue além.

Decidir sobre a entrada em um curso de hegemonia masculina demanda, para as mulheres, um posicionamento de força: o empoderamento é uma necessidade de sobrevivência naquele espaço e não uma opção, de dizer sim quando lhes dizem não, reafirmando suas escolhas pessoais. Quando indagada sobre o fato de existirem ou não profissões mais adequadas a um ou outro sexo, Maria (EP) reafirma sua batalha cotidiana: "Que nada! Tudo igual. Conheço até mulher caminhoneira. Homem e mulher podem fazer o que gostam. Mulher tem é que se impor, mostrar que pode!".

Ao adentrar no campo das engenharias, as mulheres constroem, no processo de empoderamento, marcas identitárias que implicam romper as fronteiras de gênero e produzir habilidades que são vistas ora como outras feminilidades, ora como um movimento de masculinização.

\footnotetext{
As mulheres engenheiras são iguais às outras: gostamos de nos cuidar, arrumar, tudo. Só que o nosso trabalho é diferente. Dizem que somos mais bravas, não é verdade, e que não somos sensíveis, grande engano, choro até em propaganda! Eu diria que somos mais objetivas que as pessoas que trabalham com outras áreas, como a professora [pesquisadora], mas os rapazes também agem assim. (Rita, EP)
}

Parece que agora tem bastante mulher na engenharia. Tem que ver que algumas vezes têm umas que são meio masculinas, não é? [...] Elas são mulheres fortes porque escolhem uma profissão 
Para ambas, é a profissão que define um novo jeito de ser e implica outra feminilidade, que se adequa às necessidades do trabalho. Regina aponta uma crítica, quase velada, à masculinização, que, para Faulkner (2007), significa assumir características do dominante para ser aceito por ele em uma não autenticidade de gênero, dilema que parece comum para as estudantes.

Sendo gênero relacional, mudanças nas feminilidades que geram autonomia e controle sobre a carreira acarretam mudanças nas masculinidades, retirando os homens de sua posição de conforto do patriarcado. Entre os estudantes entrevistados, encontramos algumas concepções que reafirmam o binarismo sexista e a perda de poder masculino, e outras que se apresentam neutras ou entusiastas da quebra das fronteiras de gênero e sexo nas engenharias.

[...] elas dão outras características na profissão, têm a intuição mais desenvolvida, conseguem ver coisas que a gente não vê. Mulher tem que fazer o que está a fim. Essa história de não pode já era. A mulher está fazendo coisas que antes eram só para homens [...]. Elas são iguais às outras mulheres, só que escolheram a Engenharia e isto exige que elas sejam mais firmes e impositivas. Elas têm que matar um leão por dia para mostrar o trabalho. Então, são persistentes e corajosas. É assim que vejo minhas colegas na sala. Não é fácil! (Rogério, EP)

Do grupo, Rogério foi o único que ponderou uma habilidade diferenciada, a intuição, que agregaria algo mais ao trabalho, sem afirmar que tal atributo as jogaria para um determinado setor da divisão sexual do trabalho dentro da profissão, como outras afirmações comuns no campo (PEREIRA; NORI, 2011).

Para um grupo de entrevistados predomina a visão de igualdade, ainda que os graus de empatia com as mulheres sobre as dificuldades observadas sejam variáveis. Com um discurso polido e cuidadoso, deixam nas entrelinhas a persistente masculinidade da profissão e a necessidade de as colegas criarem seus próprios caminhos.

Tem mais mulher engenheira hoje. Não vejo nada de mais, elas podem fazer o que quiserem. Cada um escolhe a profissão que quer. Elas enfrentam mais desafio, porque tem coisa que é mais difícil para mulher. (Marcos, EC) 
Atualmente tem mais mulher fazendo Engenharia, elas estão ocupando um espaço que antes era só de homem. Não sei como funciona na prática para elas, só que se querem esta profissão elas têm que batalhar por isto e pronto. Com certeza é uma escolha bem complicada. (Mauro, AG)

Aqui na civil está aumentando muito, a mulherada está invadindo tudo. Só que não tem nada, tem espaço para todo mundo. Cada um faz o que quer, se elas gostam de engenharia, tem mais é que fazer. (Alex, EC)

As mulheres estão conquistando o seu espaço, não é fácil para mulher atuar nesta área. Sou filho de uma engenheira civil e escuto minha mãe falando como foi difícil começar a trabalhar. (Ari, EC)

Aqui constatamos que o protagonismo de superação é delas, o que corresponde às falas femininas de automotivação e superação. $\mathrm{O}$ currículo não é tão oculto assim: os quatro estudantes demonstram perceber as dificuldades de as mulheres estudarem Engenharia, mas deixam claro que a luta é exclusivamente delas. Essa dinâmica das relações de gênero nos faz pensar que o embate na sala de aula, no trabalho de campo, no estágio demanda, por parte das mulheres, minoria em cada turma, uma luta diária para a permanência no curso e que, segundo as pesquisas sobre o exercício da profissão, seguirá ocorrendo depois de formadas. Esse processo de constituição de identidade acontece de modo dinâmico, produzindo sentidos contraditórios, em um processo de vir a ser.

A constituição da identidade masculina, bem como da feminina,
constituem-se como um complexo processo dialético em que as
biografias individuais entrecruzam-se com as pautas sociais histo-
ricamente construídas, onde o sujeito interativo imprime significa-
cões singulares às suas ações no mundo, ações essas inscritas em
um cenário de alternâncias, confrontos e superações. Assim, mas-
culinidades e feminilidades constituem-se em práticas múltiplas
e mentalidades correlatas, oriundas de fontes diversas, assumin-
do um caráter dinâmico e polimorfo em contínua transformação.
(SIQUEIRA, 1997, p. 115)

Ao lado da admiração ou simples aceitação da presença feminina, a masculinidade hegemônica que impera nas engenharias foi observada em outro grupo masculino, que recusou a igualdade e assumiu claramente a guerra dos sexos: 
Como eu estava falando, se nós damos mais resultado, todo mundo confia mais nos homens engenheiros. Claro que tem mulher bem boa. Sem contar que ainda tem preconceito, não é? [...] Engenharia parece mais com homem, só que tudo mudou e as mulheres estão cada dia mais se formando em Engenharia. E isto não deve ser ruim, não, elas deixam até a turma mais bonita! [...] Eu penso que elas podem fazer o curso depois a gente concorre no mercado. [...] Quem vai se dar bem? Homem ou mulher? Porque nosso desempenho é diferente! (Luiz, EP)

Tem mais mulheres engenheiras hoje, mas estão sempre na rabeira dos homens. Sempre correndo atrás. Elas deviam buscar profissões em que poderiam se destacar mais. [...] Acham que são meIhores porque fazem engenharia e depois não avançam muito. São frágeis, choram fácil. São mulheres. (Vitor, EAS)

Tem bastante mulher nos cursos aqui e até professora, coordenadora. [...] Só que eu acho que tem coisa que não é para mulher. Cada dia tem mais mulher por aqui. As mulheres não conseguem fazer tudo o que precisava fazer no campo. [...] Elas têm que fazer um curso que fique melhor para elas, não dá para fazer o que dá na telha. (Gil, AG)

Sustentar suas escolhas por carreiras que são tidas como masculinas implica, para as estudantes, romper com valores que as discriminam, enfrentando padrões de gênero aceitos no interior das famílias, nas escolas e no trabalho (LOMBARDI, 2005).

Fazer Engenharia para mulher é mais complicado, ninguém acredita muito que uma mulher pode ser uma boa engenheira. Até parece que as pessoas não gostam muito de dizer engenheira, logo falam engenheiro. Mas eu estou aqui e estou feliz! [...] mas ainda tem gente que prefere mais engenheiro. Isto me causa preocupacão, porque tem o meu futuro profissional. E fico até sem dormir pensando no que fazer depois de formada. (Lúcia, EAS)

Se for numa construtora ou empresa ou outra empresa da área os salários quase sempre são bem menores. Nós que estamos aqui sabemos que depois teremos um novo desafio que é vencer as barreiras do mercado de trabalho. Lá é uma selva de pedra, e os homens entram em vantagem. Só que estou disposta a encarar. (Ana, EC)

Segundo pesquisas como de Madalozzo e Artes (2017), os dados da Pesquisa Nacional por Amostra de Domicílios de 2013 expressam a 
desigualdade entre homens e mulheres nas engenharias, apesar do mesmo nível de formação educacional: jornada de trabalho semanal de 40 horas ou mais para $88 \%$ dos homens e $79 \%$ das mulheres; $69 \%$ de homens casados para 43\% de casadas; e diferença salarial (salário-hora) de 19\% a favor de homens engenheiros.

Apesar do conhecimento das desigualdades durante o curso ou estágios, não houve qualquer menção, pelas estudantes, de experiências coletivas de luta. As meninas se veem enquanto grupo de mulheres, no sentido abstrato e não como um sujeito coletivo capaz de mudanças sociais. As saídas apontadas são sempre individualizadas, tais como mostrarem-se competentes, prestarem concurso público ou convencerem as chefias, pouco a pouco, com a qualidade de seus trabalhos. Para algumas, como Rosa e Lia, que no começo da entrevista haviam se mostrado animadas e orgulhosas de se tornarem engenheiras em um mundo em mudança, os depoimentos tornaram-se dramáticos, ao tocarem nas questões salariais:

O que a gente vê é que se vai trabalhar na Epagri ou outra coisa
pública a mulher e homem ganharão igual. Senão, é se conformar
e pronto. Pesquisadora: Se conformar? Rosa: Não tem o que fazer,
pagam o que querem, esta é a lei dos mais fortes. (Rosa, AG)

Descobri que mesmo depois de formada devo ganhar menos que meus colegas homens. Que sacanagem! Vou dar o mesmo resultado, talvez até mais resultado e ganhar menos. Eu não entendo, então, a gente estuda e depois tem que trabalhar, cuidar dos filhos e ainda ganhar menos. Bem chato! (Lia, EAS)

Toda a demonstração de força vinha acompanhada da descrição de obstáculos na cultura acadêmica. Com exceção de duas entrevistadas, os/as demais estudantes, mulheres e homens, foram unânimes em destacar a frequente demarcação das diferenças de modo discriminatório durante as atividades de aprendizagem, junto a colegas homens e até com colegas mulheres.

Os rapazes ficam enchendo a nossa paciência, não querem fazer
trabalho de campo com a gente algumas vezes. [...] E aí tem
sempre um que diz: isso é trabalho para homem. (Lúcia, EAS)

Eles [colegas] ficam mandando elas comprarem macacão de tigresa justo que daí peão obedece... [risada] (Alex, EC)

Ninguém esconde muito que mulher não tem jeito para comandar produção. E daí vira folia na sala. Ninguém briga... algumas vezes 
briga sim, elas se incomodam. Tem colega que diz que não sabe o que elas estão fazendo aqui, que mulher só atrapalha na fábrica, vão lá e querem colocar vaso de flor em todo o lugar. (Luiz, EP)

Algumas vezes num trabalho, quando a gente divide o que cada um vai fazer, uma delas fala "deixa esta parte para ele que ele é homem, vai tirar de letra". Ou quando uma colega mulher erra e a outra diz "isso é coisa de mulher!" (Ana, EC)

Os professores também foram muito citados pelo conjunto de estudantes:

Até os professores algumas vezes dão umas sacaneadas nas meninas da sala. Teve um [professor] que disse: "no final da aula fico só com as meninas para explicar melhor este conteúdo". Ai foi zoação a aula toda. (Alex, EC)

[Os professores] quando discutem um assunto, escutam mais os guris, o que eles falam para grande parte dos professores tem mais peso. Até quando é para organizar uma saída de campo eles esquecem de nos ouvir, até brigamos algumas vezes na sala. Só que eu tenho ficado mais quieta porque não resolve. (Ana, EC)

Só uma vez um professor fez piadinha mas se desculpou. Disse que mulher era para cuidar da casa, que cuidar de negócio era para homem. Saí logo dando o exemplo da presidente da Pepsico, uma corporação multinacional de origem americana [...] Ficou todo quietinho! (Vera, AG)

Só que também os professores pensam que nem eu, até sugerem que elas se preparem para as atividades que falei antes [projeto, planta, fluxo de produção, custos] (Luiz, EP)

Não existem dúvidas de que os colegas e os professores refletem e reproduzem rótulos conforme a organização do mundo do trabalho, especialmente sobre as habilidades cognitivas. Tais discriminações nas relações de gênero agem como um contrapeso à busca do empoderamento das meninas, conforme outras pesquisas sobre a universidade (SILVA, 1999; CASAGRANDE; LIMA E SOUZA, 2017).

Para outros três estudantes que consideram "natural” a diferença, tal atitude era a única possível, já que, “de fato” homens e mulheres são diferentes e mulheres não deveriam mesmo estar nas engenharias. O ambiente da sala de aula está impregnado, por meio de piadas ou conteúdos jocosos, sobre a diferença apresentada como abissal entre 
"ser engenheiro" e as habilidades sociais ou cognitivas, vestimentas ou características físicas das mulheres. A afirmação de Maria pode sintetizar a descrença do meio acadêmico sobre a capacidade das mulheres: "Professor, coordenador e os colegas meio que não botam fé no nosso trabalho!" (Maria, EP).

O espaço acadêmico perpetua, de muitas formas, as desigualdades e fortalece a divisão sexual do trabalho. Entretanto, como vimos nas falas estudantis, as mulheres têm buscado, na educação, a mola propulsora de transformações sociais, que lhes oportuniza a inserção no mercado de trabalho, procurando construir uma ação social contra-hegemônica.

\section{OS OBSTÁCULOS DECORRENTES DO BINARISMO DE GÊNERO DENTRO E FORA DA UNIVERSIDADE}

Analisando em conjunto os sentidos das falas das entrevistadas, pudemos vislumbrar um divisor de águas com relação à naturalização das diferenças. Para metade delas, constatamos a permanência do binarismo de gênero, que se aproximava ora de certa ideia funcionalista de diferença, que se apresenta como complementaridade de habilidades, às vezes, de modo naturalizante, ora de um conservadorismo explícito sobre os significados de gênero, em que uma masculinidade é contraposta a uma feminilidade, sempre naturalizada e hierárquica. Apenas a luta pelo empoderamento não necessariamente leva a uma política de equidade, uma vez que concepções binárias operam sentidos que não rompem com a divisão sexual dentro do próprio campo das engenharias, com áreas de atuação demarcadas e produtoras de atos discriminatórios, como assédio moral e sexual, às vezes invisíveis ou vistos como naturais pelas engenheiras (LOMBARDI, 2017).

Por isso, trazemos aqui uma reflexão sobre o binarismo nas relações de gênero, tema observado por Salvador (2010), ao ressaltar características como o cuidado, a atenção, a emotividade, a falta de força física ou de inteligência para exatas atribuídas às mulheres pelos colegas, e até por elas mesmas durante a graduação ou docência. A feminização numérica não tem alterado a cultura acadêmica discriminatória (CASAGRANDE; LIMA E SOUZA, 2017), ou sequer as trajetórias profissionais que classificam e reclassificam hierarquias e espaços (LOMBARDI, 2006).

Os sentidos estéticos ou funcionais, o pensamento lógico ou intuitivo, a doçura da sensibilidade ou a firmeza da liderança, binarismos que se sucedem nas entrevistas, revelam as contradições de uma profissão que teima em se manter masculinizada e resiste à entrada das mulheres. Casagrande e Lima e Souza (2017) analisaram a persistência do quesito estético que ata mulheres à impossibilidade da graxa, do cabelo desarrumado, ou impõe a masculinização, que prejudica a permanência das estudantes nos cursos de Engenharia, questões que se apresentaram, 
também, em nosso estudo de caso. O binarismo de gênero é um recurso explicativo para Marcos e João ao responderem sobre o significado de "ser engenheiro(a)"

[...] elas se dão melhor nos acabamentos da obra, na estética, fazem um projeto com beleza. Nossos projetos são mais funcionais, a beleza fica em segundo plano, conseguimos aproveitar melhor o terreno. As meninas têm mais dificuldades nas disciplinas de cálculos e de estradas, e também no estágio. (Marcos, EC)

Eu não sei explicar direito, mas tem disciplinas que as mulheres vão melhor e tem outras que são os homens. Coisa da natureza. Mulher se dá bem na estética dos projetos, na organização. Homens nos cálculos. Não sei porque, mas acontece dessa forma no curso. (João, EC)

Observa-se esse sentido dicotômico em relação ao simbólico generificado da atuação profissional de homens e mulheres, delimitando habilidades e segmentos profissionais no trabalho. No campo da cognição persiste a crença de que naturalmente os homens são mais hábeis para algumas práticas e aprendizagens na área.

Mulher consegue organizar melhor, cuidar da beleza, tratar as pessoas melhor. Homem é mais rápido e prático. Então, na aula é igual, mulher até tira nota mais alta que homem, é mais dedicada, eu acho. Só que quando entramos numa produção, a planta parece que é a nossa casa e para elas não é assim. Sem contar que elas não gostam de trabalhar de touca ou capacete, sapatão, protetor. Elas gostam de estar bonitas. (Luiz, EP)

Novamente, o velho rol de diferenças dicotômicas: habilidade relacional versus praticidade; dedicação aos estudos versus inadequação em campo. Por fim, a excessiva preocupação com a estética, inadequação impossível de ser transposta! Curiosamente, tal estética não apareceu nos depoimentos das entrevistadas como necessidade, mas como negação. E mesmo inserindo-se em profissões reconhecidas como eminentemente masculinas e sendo protagonistas desse enfrentamento, pesquisadoras apontam que as mulheres reconhecem haver, na profissão, segmentações e, por vezes, se moldam a elas:

[...] as engenheiras são selecionadas para atividades que envolvem relacionamento interpessoal ou trabalhos dentro de escritórios, enquanto os engenheiros são encaminhados para canteiro de obras ou trabalhos de programação, considerados trabalhos mais 
técnicos, que, por sinal, são melhores remunerados. (CARVALHO, 2007, p. 47)

Essas informações são dadas como fato social, de luta para algumas e de medo e insegurança para outras.

Temos percebido que sim, nossas professoras mulheres falam sobre isto. Mas acho que não é só nas engenharias. Não é muito fácil ser mulher. Tem muita exigência. Como que nós fazendo a mesma coisa ganhamos menos? Está tudo errado. Parece que os homens nasceram para ser chefes, se tiverem que escolher logo chamam o homem para promover e a gente vai ficando. Aqui a maioria dos colegas homens já está montando empresa e contratando a gente como estagiária. Eu mesma sou estagiária do Ivan. Isto eu me questiono todos os dias quando vou trabalhar! (Lucia, EAS)

Durante o processo formativo, as estudantes já sabem o que as aguarda. A compreensão da diferença corresponde aos dados sobre o mercado de trabalho, fixando áreas femininas, como planejamento e desenvolvimento. Os cursos de formação em Engenharia têm criado condições para a entrada das mulheres; entretanto, as posições que elas ocupam no mercado demonstram ser restritas a determinadas atividades, consideradas menos duras (LOMBARDI, 2005).

Poucas, como Maria, tecem uma ampla crítica ao binarismo, e o nega a partir das experiências que analisa em seu curso. Ana mostra-se ambígua, dividida entre o que observa na sala e o discurso docente.

Só que todo mundo diz que homem consegue ter mais noção de espaço [...] por exemplo, quando se fala em fluxo de produção eles sabem organizar melhor, porque olham para as coisas e sabem se cabe lá ou não. Só que não sei não. Na sala tem cara que se dá supermal, reprova e tudo. Eu não, nunca reprovei, tiro notas bem boas, até fiquei em exame, mas foi por pouco. (Maria, EP)

Não, homens e mulheres aprendem igual, não entendo muito deste negócio, na sala todos aprendem. Eu penso que sim. Só que parece, algumas vezes, que na hora do cálculo os guris pegam mais rápido. Mas notas são parecidas. Mas o professor falou um dia que homem é melhor em pensamento lógico, então penso que isso faz parte. (Ana, EC)

Para Ana, o fiel da balança recai sobre a afirmação do professor, autoridade sobre a aprendizagem e que não é visto, pela estudante, como um porta-voz do sexismo, que assim age, talvez, sem refletir sobre 
o peso de suas afirmações para a construção da subjetividade da aluna. Maria, por outro lado, no ir e vir concreto das contraditórias relações sociais, permeado pelo que simbolicamente constitui sua subjetividade, considera-se uma boa aluna, e suspeita da supremacia masculina em um processo de consciência de si, que busca construir outros simbolismos e formas de ser e estar no mundo.

Sobre os resultados de aprendizagem, observamos que eles são um ponto sempre presente de classificação entre os sexos e que poderiam ser problematizados por professores/as das engenharias. Vejamos falas femininas sobre a possível diferença de aprendizagem:

\begin{abstract}
Quando a gente está trabalhando área, cálculo, eles entendem mais que a gente. Quando vão numa obra eles conseguem olhar para o espaço e visualizar a obra pronta mais rápido. Homem tem dessas coisas, rapidinho pegam o jeito, acho que na Civil é assim mesmo. E ai eles conseguem melhores notas no que fazem. [...] Isto acontece sempre, é que mulher demora para entender. Tem piada que eles fazem que a gente não entende, só falam "só podia ser mulher". E até eu [também penso sobre as mulheres] porque tem umas lá que perguntam coisa do além, parecem fora da casinha. (Regina, EC)
\end{abstract}

Não. Só naquelas engenharias mais duras mesmo, como a Engenharia Civil. Parece que os homens conseguem resolver meIhor as coisas lá na Civil. Na minha sala tudo igual, tem homem que vai bem e mulher também. Claro que alguns se acham os bons, mas eu não dou a menor importância. Só que tem o Carlos que é fera, só vê as coisas e já sabe fazer, ele mesmo nasceu para ser engenheiro! (Lia, EAS)

A naturalização das características atreladas socialmente à mulher está em ambas as narrativas, expressando uma interiorização da incompetência e inferioridade, como em Regina. Para Lia, outros elementos contraditórios aparecem: igualdade de aprendizagem em geral, mas naturalização de habilidade em um homem... O fato de estudarem Engenharia e romperem alguns estereótipos não significa uma ruptura com a naturalização.

Entre as entrevistadas, Vera foi incisiva sobre as capacidades iguais, demonstrando uma identidade coletiva positiva: "Não [há diferença de aprendizagem] Eu aprendo igual a qualquer metido por aí. Tenho notas bem boas até nas aulas práticas. Não perco para nenhum machinho aí e minhas amigas também!" O uso das palavras expressa quase uma guerra entre os sexos: a estudante não está apenas respondendo à pesquisadora, mas aos colegas homens e às colegas mulheres que insistem em expressar a diferença 
de aptidão entre homens e mulheres em exatas (CABRAL; BAZZO, 2005; SARAIVA, 2008).

Lombardi (2006) constatou que o aumento de mulheres nos cursos de engenharia vem carregado de reações variadas e/ou adversas, resistências masculinas, por vezes vinculadas a mecanismos de controle sociais, o que pode levar as discentes de Engenharia, e mesmo as profissionais, à posição de subordinação. Dessa maneira, são reproduzidas as relações de poder hierarquizadas que têm, ainda, constituído esse campo de atuação acadêmico profissional.

Com justificativas, às vezes naturalizantes, outras vezes ambíguas, as/os estudantes entrevistadas/os destacam a diferença em relação à liderança:

Quando o gerente de produção é homem, vejo lá no trabalho, ele tem mais força para liderar. Acho que nós que nascemos mulheres nunca aprendemos a liderar. Fomos educadas para obedecer, a senhora pode ver nossas mães, elas sempre aceitam tudo. (Rita, EP)

Sim, a gente é mais doce, mais boazinha, delicada. O homem é mais grosso, sabe mandar mais. Então, todo mundo pensa que ele é melhor como engenheiro e ele tem mais cliente, acreditam mais em engenheiro homem. (Regina, EC)

[...] Ninguém esconde muito que mulher não tem muito jeito para comandar produção! (Luiz, EP)

Além das origens militares que conferem certo autoritarismo à profissão no trato com trabalhadores, ressaltamos que, em uma sociedade capitalista, o poder de mando está atrelado à dominação de classe, sendo expresso sempre em diferentes graus de autoritarismo. Como tal modo de liderar tende a ser hostil às mulheres, cuja liderança aprendida para as relações familiares é relacional e voltada ao cuidado, elas se veem em um beco sem saída. De qualquer forma, ambos os sexos não parecem questionar os modos de chefia, hierárquicos e agressivos, que são esperados dessa profissão. Marcos, que já se manifestou em outro momento como defensor da igualdade entre os sexos, consegue ver, ao menos, o sexismo com o qual ele não compartilha:

Não sei se tem muita diferença, mas parece que todo mundo quer mais engenheiro homem. Parece que ainda olham estranho. Na obra é bem complicado, a macharada não dá trégua quando a engenheira é mulher, pega pesado. (Marcos, EC) 
O caminho profissional de mulheres que adentram a área tecnológica é um trajeto árduo, repleto de enfrentamentos. Elas encontram resistências na conquista de espaço e respeitabilidade profissional, e esse caminho não tem volta. Todavia, ao permanecerem situadas em um binarismo conservador ou em saídas individualizantes, mesmo defendendo igualdade de condições para ambos os sexos, as (estudantes) engenheiras deixam de buscar mudanças coletivas nessa identidade profissional resultante da ordem patriarcal. Como afirma Figueiredo (2008, p. 30):

\begin{abstract}
Embora o ingente esforço dessas mulheres, pelo reconhecimento e igualdade de oportunidades no campo profissional, operam em sentido contrário a essa mobilização pela eqüidade de gênero, os artefatos, as organizações sindicais, as políticas de trabalho, o processo industrial e o mercado que culminam na marginalização das engenheiras nos processos de concepção e produção tecnológicos.
\end{abstract}

Essa é a razão de vermos com bons olhos os movimentos políticos das estudantes de engenharias conforme se constata nos registros dos sucessivos Encontros Nacionais de Engenharia e Desenvolvimento Social (ENEDS), ${ }^{3}$ que tratam da produção científica e de embates políticos. A frase de Marcos - “a macharada não dá trégua” - expressa, de modo sintético, o longo caminho a percorrer.

\title{
CONSIDERAÇÕES FINAIS
}

É inegável o aumento da inserção da mulher ao ocuparem espaços reconhecidos como masculinos, transformando as relações de poder-subordinação e criando formas de enfrentamento da divisão sexual do trabalho. A partir das narrativas de estudantes de Engenharia, em diálogo com outras pesquisas sobre o período estudado, pudemos compreender o momento histórico contemporâneo e de como estudantes de Engenharia experienciam, durante a graduação em Engenharia, as relações de gênero. A partir de dois eixos de análise, o empoderamento e os binarismos de gênero, tecemos reflexões sobre as rupturas e permanências que tem se dado nesses espaços.

As escolhas por áreas tradicionalmente masculinas implicam um movimento de subversão, representando um risco às relações patriarcais e, de certa forma, destituindo os homens de uma posição reinante de poder, na mesma medida em que esse poder passa a ser compartilhado por mulheres. As estudantes de Engenharia posicionam-se de forque, dentro desses campos de saber, foram se constituindo novos guetos masculinos e femininos, os quais mantêm a divisão sexual do trabalho. 
Constatamos que, para uma parcela significativa das estudantes, afirma-se a dualidade naturalizante e dicotômica. Os sentidos subjetivos apresentados nos relatos de parcela das/dos estudantes mostram-se vinculados à ideia de uma essência natural do feminino e do masculino, explicitando concepções dicotômicas/binárias de masculinidades e feminilidades. Essa forma de ver, ainda que não impeça essas mulheres de seguir estudando, reforça segmentações na profissão e conformismos que dificultarão transformações substanciais.

Entretanto, os espaços de formação mostram-se contraditórios, indicando que as subjetividades em conflito permitem um processo de consciência de si e de (re)construção de novos simbolismos, novas formas de ser e estar no mundo, produzindo mudanças sociais. Em todos os contextos sociais, inclusive na formação superior, os sentidos são continuamente negociados, o que se torna visível nos contrapontos que indicam avanços das mulheres para um campo concebido como espaço de masculinidades, porém ainda permeados por relações de poder que as situam como subordinadas.

Na IES estudada, o sexismo apresenta-se sob a forma de pressão em sala, com ironias e outras atitudes que diminuem as mulheres, no que concerne à apropriação de competências técnico-científicas em um emaranhado relacional discriminatório nas relações docentes-discentes, revelando, também, que docentes, sobre os quais recai a responsabilidade de formação, são sexistas de uma maneira bastante explícita. Os estudantes expressam o sexismo de modo contraditório, ora denunciando a discriminação, mas atribuindo a luta às colegas, ora compactuando com as discriminações e juntando-se aos docentes.

No que concerne às engenharias, a segregação espacial e diferenças salariais na sociedade são visíveis para as estudantes da área. O caminho advindo do feminismo, na busca das mulheres por reconhecimento e autonomia, parece ainda ganhar nuances frágeis, enquanto possibilidade vislumbrada por essas estudantes.

A partir das análises, podemos corroborar com os dados mais gerais da última década, de que houve um aumento na inserção de mulheres nas profissões ainda consideradas hegemonicamente masculinas, como as engenharias, mas destacamos que esses avanços ainda vão de encontro a concepções sexistas presentes no mundo acadêmico e profissional. Assim, a universidade constitui-se como um espaço de luta permanente para mulheres estudantes e futuras profissionais engenheiras. Ressaltamos as estratégias de empoderamento, como possibilidade de avanço e a presença de binarismo, hierárquico e naturalizante, como conservadorismo que persiste.

As alternativas coletivas, enquanto movimentos organizados na universidade ou profissionalmente, a exemplo dos encontros, órgãos de representação estudantil ou representação profissional, não aparecem 
como horizonte de luta para as estudantes, sendo comuns as buscas individuais ou o conformismo. A vivência nos cursos de Engenharia aparece como um momento eivado de contradições, que poderia ser problematizado junto a estudantes e professores/as, visando a dar suporte para a permanência das alunas na universidade e instrumentalizando-as para suas entradas no mercado de trabalho de maneira mais segura. Tal processo demanda ações dentro e fora da universidade, caso se deseje, de fato, romper as amarras que, se não impedem as mudanças devido à luta das mulheres na conquista desse campo tradicionalmente masculino como a engenharia, ainda resultam em muita lentidão para as transformações almejadas. Cabe lembrar aqui a necessidade da construção de referências positivas durante a educação básica, que desconstruam os estereótipos de gênero em relação às aprendizagens e futuras carreiras.

A compreensão naturalizante do que é ser homem ou ser mulher nos cursos de graduação necessita ser problematizada a partir de experiências coletivas de ação política ou de formação, que permitam ao sujeito questionar a constituição das relações de gênero e demais marcadores sociais em todas as conexões sociais, históricas e culturais em que estão inseridas.

\section{REFERÊNCIAS}

ANTUNES, Ricardo. Trabalho, reestruturação produtiva e algumas repercussões no sindicalismo brasileiro. In: ANTUNES, Ricardo (Ed.). Neoliberalismo, trabalho e sindicato: reestruturação produtiva na Inglaterra e no Brasil. São Paulo: Boitempo, 1997. p. 71-84.

BRASIL. Ministério da Educação; Instituto Nacional de Estudos e Pesquisas Educacionais Anísio Teixeira. Censo da educação superior 2011: resumo técnico. Brasília: Inep, 2013. Disponível em: <http://download.inep.gov.br/download/superior/censo/2011/resumo_tecnico_censo_educacao_ superior_2011.pdf >. Acesso em: 27 set. 2016.

BRASIL. Ministério da Educação; Instituto Nacional de Estudos e Pesquisas Educacionais Anísio Teixeira. Censo da Educação Superior: evolução - 1980 a 2007. Brasília: Inep, 2009. Disponível em: <http://www4.inep.gov.br/web/censo-da-educacao-superior.html>. Acesso em: 14 abr. 2015.

BRASIL. Presidência da República. Secretaria Especial de Políticas para as Mulheres. Pensando gênero e ciência. In: ENCONTRO NACIONAL DE NÚCLEOS E GRUPOS DE PESQUISAS 2009/2010, 2. 2010. Pensando gênero e ciências. Brasília: Secretaria Especial de Políticas para as Mulheres, 2010. 198 p.

BRASIL. Secretaria de Políticas Públicas para Mulheres; ONU MULHERES; Instituto de Pesquisa Econômica Aplicada. Retrato das desigualdades de gênero e raça. 2016. Disponível em: <http://www.ipea.gov.br/retrato/indicadores_trabalho_domestico_remunerado.html>. Acesso em: 20 abr. 2017.

BRUSCHINI, Maria Cristina Aranha. Mulher e trabalho: engenheiras, enfermeiras e professoras. Cadernos de Pesquisa, São Paulo, n. 27, p. 5-17, dez. 1978.

CABRAL, Carla Giovana; BAZZO, Walter Antonio. As mulheres nas escolas de engenharia brasileiras: história, educação e futuro. Revista de Ensino de Engenharia, Passo Fundo, v. 24, n. 1, p. 3-9, jan./jun. 2005.

CALAFIORI, Luciano. Mulheres conquistam espaço e humanizam a carreira de engenharia. G1, Campinas, 24 abr. 2013. Disponível em: <http://g1.globo.com/sp/campinas-regiao/ noticia/2013/04/mulheres-conquistam-espaco-e-humanizam-carreira-de-engenharia.html>. Acesso em: 10 jul. 2013. 
CARVALHO, Marilia Gomes de. Gênero e tecnologia: estudantes de engenharia e o mercado de trabalho. In: SEMINÁRIO INTERNACIONAL MERCADO DE TRABALHO E GÊNERO: COMPARAÇÕES BRASIL-FRANÇA. 2007, São Paulo. Anais... São Paulo: Fundação Carlos Chagas, 2007. v. 1. p. $1-12$.

CARVALHO Marilia Gomes de; SOBREIRA, Josimeire de Lima. Gênero nos cursos de engenharia de uma universidade tecnológica brasileira. ARBOR Ciencia, Pensamiento y Cultura, v. 184, n. 733, p. 889-904, set./out. 2008.

CASAGRANDE, Lindamir Salete; LIMA E SOUZA, Ângela Maria Freire de. Percorrendo labirintos: trajetórias e desafios de estudantes de engenharias e licenciaturas Cadernos de Pesquisa, São Paulo, v. 47, n. 163, p. 168-200, jan./mar. 2017.

COSTA, Suely Gomes. Proteção social, maternidade transferida e lutas pela saúde reprodutiva. Revista Estudos Feministas, Florianópolis, v. 10, n. 2, p. 301-324, jul./dez. 2002.

FAULKNER, Wendy. Nuts and bolts and people: gender-troubled engineering identities. Social Studies of Science, Thousand Oaks, CA, v. 37, n. 3, p. 331-356, jun. 2007.

FEDERAÇÃO INTERESTADUAL DE SINDICATOS DE ENGENHEIROS - FISENGE. CREA-PB incentiva participação da mulher engenheira em espaços de debate. João Pessoa, 03 mar. 2017. Disponível em: <http://fisenge.org.br/index.php/noticias/item/3768-crea-pb-incentivaparticipacao-da-mulher-engenheira-em-espacos-de-debate>. Acesso em: 20 abr. 2017.

FIGUEIREDO, Luiz Carlos de. 0 gênero na educação tecnológica: uma análise de relações de gênero na socialização de conhecimentos da Área de Construção Civil do Centro Federal de Educação Tecnológica de Mato Grosso. 2008. 148f. Dissertação (Mestrado) - Universidade Estadual de Campinas, Campinas, 2008.

GONZALEZ REY, Luiz Fernando. Pesquisa qualitativa e subjetividade: os processos de construção da informação. São Paulo: Pioneira Thomson Learning, 2005.

HIRATA, Helena. Nova divisão sexual do trabalho? Um olhar voltado para a empresa e a sociedade. São Paulo: Boitempo, 2002.

KERGOAT, Danièle. Penser la différence des sexes: rapports sociaux et division du travail entre les sexes. In: MARUANI, Margaret (Dir.). Femmes, genre et sociétés. Paris: La Découverte, 2005. p. 94-101. (L'état des savoirs).

LEON, Magdalena. Empoderamiento: relaciones de las mujeres con el poder. Revista Estudos Feministas, Florianópolis, v. 8, p. 191-201, 2000.

LOMBARDI, Maria Rosa. Perseverança e resistência: a Engenharia como profissão feminina. 2005. 279 f. Tese (Doutorado) - Universidade Estadual de Campinas, Campinas, 2005.

LOMBARDI, Maria Rosa. Engenheiras brasileiras: inserção e limites de gênero no campo profissional. Cadernos de Pesquisa, São Paulo, v. 36, n. 127, p. 173-202, jan./abr. 2006.

LOMBARDI. Maria Rosa. Engenheiras na construção civil: a feminização possível e a discriminação de gênero. Cadernos de Pesquisa, São Paulo, v. 47, n. 163, p. 122-146, jan./mar. 2017.

MADALOZZO, Regina; ARTES, Rinaldo. Escolhas profissionais e impactos no diferencial salarial entre homens e mulheres. Cadernos de Pesquisa, São Paulo, v. 47, n. 163, p. 202-221, jan./mar. 2017.

MENEZES, Marcia Barbosa; LIMA E SOUZA, Ângela Maria Freire de. Escolhas marcadas pelo gênero - sobre o ingresso de jovens mulheres e homens nos cursos de graduação da área de exatas na UFBA. In: SEMINÁRIO INTERNACIONAL ENLAÇANDO SEXUALIDADES, 3., 2013, Salvador. Anais... Salvador: Uneb, 2013. p.1-14. Disponível em: <http://www.uneb.br/ enlacandosexualidades/2013/06/13/1735/>. Acesso em: 10 jan. 2016.

MOREIRA, Antonio Flavio Barbosa; CANDAU, Vera Maria. Indagações sobre currículo: currículo, conhecimento e cultura. Brasília, DF: MEC/SEB, 2007.

NOGUEIRA. Claudia Mazzei. As relações sociais de gênero no trabalho e na reprodução. Aurora, Marília, n. 6, p. 59-62, ago. 2010. 
PEREIRA, Simone Baía; NORI, Marcia Angela (Org.). Principais direitos das mulheres profissionais. Rio de Janeiro: Fisenge, 2011.

ROSEMBERG, Fúlvia; MADSEN, Nina. Educação formal, mulheres e gênero no Brasil contemporâneo. In: BARSTED, Leila Linhares; PITANGUY, Jacqueline (Org.). 0 progresso das mulheres no Brasil 2003-2010. Rio de Janeiro: Cepia; Brasília: ONU Mulheres, 2011. p. 390-434.

SAFFIOTI, Heleieth Iara Bongiovani. Rearticulando gênero e classe social. In: COSTA, Albertina Oliveira; BRUSCHINI, Cristina (Org.). Uma questão de gênero. Rio de Janeiro, São Paulo: Rosa dos Tempos, Fundação Carlos Chagas, 1992. p. 183-215.

SALVADOR, Sileide France Turan. Gênero na engenharia: o corpo docente em Curitiba, PR. 2010. 141f. Dissertação (Mestrado) - Universidade Tecnológica Federal do Paraná, Curitiba, 2010.

SANTOS, Jacqueline A. dos; SOUZA, Nádia F. de; ATOLINI, Tarcilia M. Gênero e raça na formação em engenharia no Brasil: breve análise histórica e o caso da Universidade Federal dos Vales do Jequitinhonha e Mucuri. In: ENCONTRO NACIONAL DE ENGENHARIA E DESENVOLVIMENTO SOCIAL - ENEDS, 13., Florianópolis. Anais... Florianópolis, 2016. p. 1-24. Disponível em: <http://eneds.net/ocs/index.php/edicoes/eneds2016/paper/view/271>. Acesso em: 06 jun. 2017.

SARAIVA, Karla. Produzindo engenheiras. Revista de Ensino de Engenharia, Passo Fundo, v. 27, n. 1, p. 48-56, jan./jun. 2008.

SEN, Amartya Kumar. Desigualdade reexaminada. Rio de Janeiro: Record, 2001.

SILVA, Décio. O engenheiro que as empresas querem hoje. In: LINSINGEN, Irlan von Luiz Teixeira do Vale Pereira; CABRAL, Carla Giovana. Formação do engenheiro: desafios da atuação docente, tendências curriculares e questões de educação tecnológica. Florianópolis: EDUFSC, 1999. p. 77-88.

SILVA, Paula; SAAVEDRA, Luisa. Guião de educação gênero e cidadania. Lisboa: CIG, 2009.

SIQUEIRA, Maria Juracy Tonelli. A constituição do sujeito e a divisão sexual do trabalho na família: análise do caso de um homem dono-de-casa. 1997. Tese (Doutorado) - Universidade de São Paulo, São Paulo, 1997.

VELHO, Lea; LEÓN, Elena. A construção social da produção científica por mulheres. Cadernos Pagu, Campinas, n. 10, p. 309-344, jan. 1998. 